\title{
Simposio Internacional: La etnohistoria. Fronteras transdisciplinarias en la producción del conocimiento
}

Sucre, 23-25 de abril de 2008

Isabelle Combès

\section{(2) OpenEdition}

Journals

Edición electrónica

URL: http://journals.openedition.org/bifea/3178

DOI: $10.4000 /$ bifea.3178

ISSN: 2076-5827

Editor

Institut Français d'Études Andines

Edición impresa

Fecha de publicación: 1 agosto 2008

Paginación: 414-415

ISSN: 0303-7495

\section{Referencia electrónica}

Isabelle Combès, «Simposio Internacional: La etnohistoria. Fronteras transdisciplinarias en la

producción del conocimiento », Bulletin de l'Institut français d'études andines [En línea], 37 (2) | 2008,

Publicado el 01 febrero 2009, consultado el 26 noviembre 2020. URL : http://journals.openedition.org/ bifea/3178; DOI : https://doi.org/10.4000/bifea.3178

\section{cc) (†)}

Les contenus du Bulletin de l'Institut français d'études andines sont mis à disposition selon les termes de la licence Creative Commons Attribution - Pas d'Utilisation Commerciale - Pas de Modification 4.0 International. 


\section{SIMPOSIO INTERNACIONAL: LA ETNOHISTORIA. FRONTERAS TRANSDISCIPLINARIAS EN LA PRODUCCIÓN DEL CONOCIMIENTO}

Sucre, 23-25 de abril de 2008

Calificado de «simposio internacional e interdisciplinario», lo fue en efecto desde su organización, en la cual colaboraron historiadores, antropólogos, arqueólogos y archivistas de diferentes países e instituciones: Archivo y Biblioteca Nacionales de Bolivia (ABNB), Instituto Francés de Estudios Andinos (IFEA), Antropólogos del Sur Andino (ASUR, Bolivia), Centro de Investigaciones y Estudios Superiores de Antropología Social (CIESAS, México) y University of New Mexico, Latin American and Iberian Institute (UNM/LAII, Estados Unidos). 
La etnohistoria se encuentra en la intersección de varias disciplinas (historia, antropología y arqueología en particular) que tienen sus propios conceptos metodológicos y teóricos; a esta situación se suman las diferentes tradiciones o escuelas nacionales en la producción del conocimiento. El objetivo del simposio fue, en una primera instancia, reconocer las barreras disciplinarias y nacionales que separan a los investigadores, para poder traspasarlas y lograr un real avance interdisciplinario en la producción de la investigación etnohistórica. En una segunda instancia, un tema recurrente de las ponencias y las discusiones abarcó los problemas éticos y políticos acerca del uso de los conocimientos generados y la participación de los mismos sujetos de estudio en el proceso de investigación.

El simposio fue dividido en seis sesiones de trabajo: (1) la arqueología, la historia temprana y la antropología; (2) el coloniaje, las sociedades coloniales y la etnohistoria; (3) las tradiciones en la etnohistoria en las diferentes literaturas e idiomas y en las distintas tradiciones nacionales; (4) los pueblos indígenas, las tradiciones locales y el estado nacional; (5) la historia contemporánea, el Estado y los pueblos indígenas; y (6) los archivos, las bibliotecas y la construcción de la memoria popular. Participaron como ponentes arqueólogos, historiadores, antropólogos y archivistas de Bolivia, México, Brasil, Chile, Perú, Francia y Estados Unidos. Tres mesas redondas de discusión, incluyendo la participación del público, fueron organizadas: la primera versó acerca de problemas metodológicos: «¿Cómo compaginar los métodos de trabajo entre las diferentes disciplinas que confluyen en la etnohistoria?»; la segunda abordó «la participación de los sujetos de estudio en el proceso de investigación, la producción de 'conocimientos útiles' y las investigaciones iniciadas por las comunidades mismas»; la tercera y última estuvo dedicada a temas más generales, que permitieron sacar conclusiones del simposio, como «la utilización de nuevas herramientas de análisis como la cartografía, los sistemas de información geográfica y el arte visual; el paisaje y el espacio como conceptos centrales para la etnohistoria».

Los participantes coincidieron en considerar más a la etnohistoria como un terreno abierto y un enfoque necesariamente multidisciplinario que como una disciplina en sí regida por métodos y corrientes propias de pensamiento. Fue necesario aclarar, en particular para el público universitario, los conceptos de etnohistoria o antropología histórica, que no se reducen a una simple «historia de indígenas». En el transcurso del simposio y de las discusiones, el tema de la participación de los sujetos en la investigación y, en particular, la apropiación por los sujetos de los resultados de las investigaciones para la producción de un «pasado útil», tomó mayor importancia que la prevista y se tornó en un eje central de las reflexiones. Esta importancia refleja una situación relativamente nueva en las ciencias sociales, que muestra que están cayendo las barreras entre académicos y sujetos de investigación mediante la difusión y la apropiación de los conocimientos producidos.

El auditorio incluyó a los maestros docentes y los estudiantes de la licenciatura en historia de la universidad San Francisco Xavier, universidad estatal ubicada en Sucre, además de periodistas, investigadores registrados en el ABNB, los propios empleados de la institución, y miembros interesados del público. Los asistentes inscritos para el simposio así como los participantes con ponencia y los moderadores de las mesas y sesiones de trabajo, recibieron certificados de constancia. Los organizadores del Simposio reconocen y agradecen los apoyos financieros y profesionales del Archivo y Biblioteca Nacionales de Bolivia, Antropólogos del Sur Andino, el Instituto Francés de Estudios Andinos, el Centro de Investigaciones y Estudios Superiores de Antropología Social, y la University of New Mexico, sin los cuáles no hubiera sido posible llevarlo a cabo con los resultados y beneficios que ha rendido. 